\title{
A FIGURA FEMININA E O INSÓLITO NO CONTO SIBILA, DE MÉNDEZ FERRÍN
}

Joana D'arc Santos de Oliveira do CARMO

Pode-se supor que este conto permite a Xosé Luiz Méndez Ferrín apresentar determinada carga simbólica e cultural que envolve a figura feminina ao longo dos tempos; observando-se que à mulher sempre foi atribuído o poder sobre os homens, cabendo a ela decidir acerca do destino das pessoas. Assim, para realizar seu objetivo o autor estabelece uma interação entre textos, ou seja, existe "um diálogo intertextual com um texto oculto que intermedeia entre o significado histórico e o significado atual", (Portugal, 2004: 7).

O mundo dos fatos históricos e o mundo da ficção, se a princípio são antagônicos, eles podem conviver harmonicamente, pois as impressões formuladas pelo historiador proporcionam lacunas que, por sua vez, precisam ser preenchidas e, desta forma, introduzida a escrita literária, pois:

A literatura envolve uma dimensão sociocultural, directamente decorrente da importância que, ao longo dos tempos, ela tem tido nas sociedades que a reconheciam (e reconhecem) como prática ilustrativa de uma certa consciência colectiva, dessas sociedades;

$\mathrm{Na}$ literatura é possível surpreender também uma dimensão histórica, que leva acentuar a sua capacidade para testemunhar o devir da História e do Homem e os incidentes de percurso que balizam esse devir (Reis, 2001: 24).

Essa narrativa de Ferrín se enquadra no gênero denominado conto, visto ser um texto de pequena extensão, contendo poucos personagens:

não há dúvida de que esta limitação de extensão arrastou outras limitações que tendem a ser observadas: um reduzido elenco de personagens, um esquema temporal restrito, uma ação simples ou pelo menos apenas poucas acções separadas, e uma unidade de técnica e de tom (...) que o romance é muito menos capaz de manter (Bonheim, apud Reis, 2001: 79).

O personagem narrador, no início do conto, sabe que será visitado por Sibila e sofrerá os mesmos reveses de Domingos Areal. Ele relembra a figura desse seu amigo em uma noite fria de 1925, quando encontrou o anel brilhando muito na Rua dos 
Loureiros, em frente a casa número 5, aquela do triângulo. A seguir, Domingos Areal o colocou no dedo mindinho de sua mão esquerda. O objeto era ornamentado por símbolo igual a elipse, fato propiciador de atmosfera misteriosa. Cabe dizer que, as lembranças do narrador ocorrem por força de recurso literário designado por analepse. Tal expressão é compreendida como sendo "o movimento temporal retrospectivo destinado a relatar eventos anteriores ao presente da acção e mesmo, nalguns casos, anteriores ao seu início" (Lopes e Reis, 2000: 29).

Antes de dar continuidade às lembranças, o narrador apresenta a convicção de que o terror e a violência, quando são habilmente manipulados, provocam danos irreparáveis no ser humano, conforme pôde constatar nos olhos do amigo que "representanseme os ollos escuros do difícil e duro poeta e debuxante Domingos Areal. Perdidos xa pra sempre e testemuña das raigañas da vileza" (Ferrín, 1980: 13). Na seqüência dos pensamentos a personagem repassa todos os momentos junto ao companheiro, acentuando a presença do anel e sua influência maléfica:

En cada caso a sortealla, coa elipse, locía no seu dedo e, progresivamente, a palidez ia asombrando as fazulas de Domingos Areal, a violeta situárse no basamento dos seus ollos (acibeche estremecido), o peso dunha cousa abominábel pandeáballe as costas con esmero ruín, um terremoto intermitente trabucáballe verbas, e dentes doidos comportábanse en jazz-band mentres o cuspe seu era proxectado na miña sofrida face del fidel amigo (Ferrín, 1980: 14).

Atente-se para o fato do narrador ser homodiegético, participante e relator da narrativa, ou seja: "é a entidade que veicula informações advindas da sua própria experiência diegética; quer isto dizer que, tendo vivido a história como personagem, o narrador retirou daí as informações de que carece para construir o seu relato" (Lopes e Reis, 2000: 265). Dessa maneira, para ele, o narrador, o citado adorno está intimamente associado à imagem de uma mulher sem precedentes, cuja aparição nos sonhos de Domingos, no início era desejada, porque ela:

Atraguíao ao seu seo e o delírio sobrevinã nunha cópula doce [...]. Non cabía na linguaxe de Domingos acumulación tal de pracer e fermosura, sonido e discusión de cores e mensaxes de luz e perda progresiva da entidade propia: parola na Quinta Angustia. Domingos chegara ao ponto de cáseque non comer nin fumar na noite en que Sibila, esplendente, chegara 
empunãndo unha parabellum, cunha fita cruel em vez de labres (Ferrín, 1980: 16).

Todavia, com o passar do tempo tal situação se modifica, pois Sibila, se torna ameaçadora, aterrorizante para o rapaz:

Devecía; perdia peso; alonxábase do café e do paseo; procurábame a min pra confidencia. Como avanzaba na dirección da morte! Como padeceu até o derradeiro estertor (que eu adiviño horrendo desatarse) com displicência digna dun herói estóico (Ferrín, 1980: 14).

Ele ansiava demonstrar para todas as pessoas aquela imagem que o rondava, e, estava tão envolvido pela visão que consegue desenhá-la com perfeição, de forma bastante nítida:

Da cuadrícula do papel emanaba unha face de muller pesada, lenemente forte (coma os cilindros de Santa Clara, en contraluz, certos crepúsculos), absolutamente tépeda, ollos asustados e doces coma prados ou cristal dos regueiros que percorren as devesas de faias sen que endexamais o sol os fira, labres grosos que amosaban algún medo infantil e de veludo, xesto de universal perplexidade. "É a Sibila Délfica!" Exclamei no intre (Ferrín, 1980: 15).

Assim, torna-se possível constatar que tal traço remonta à imagem da Sibila Délfica, a qual seria eternizada por Miguel Ângelo na capela Sistina.

Esses acontecimentos se sucedem até a desencarnação do rapaz atormentado. Ressalta-se, entretanto, que esses fatos tornam-se cíclicos, repetitivos, porque o próprio narrador será, em breve, mais uma vítima daquela criatura. Verifica-se nessa narrativa o convívio de tensões por conta de situações contraditórias; Sibila é, ao mesmo tempo, uma personagem detentora do prazer e da morte. Domingos Areal, em suas próprias palavras, reconhece este poder que emana da mulher quando confessa "estou desexando que veña a noite pra sofrir e pra somar" (Ferrín, 1980: 17). Portanto, faz-se adequado a apresentação a respeito desse ser constituído de atributos característicos.

Na história da mitologia grega, Sibila é jovem, mulher responsável por fazer adivinhações. Segundo Junito Brandão, "Sibila é, pois, o nome de uma sacerdotisa encarregada de transmitir os oráculos de Febo Apolo [...] Sibila adquiriu tal reputação como mântica, que todas as demais profetisas adotaram-lhe o nome" (1991: 380-1). 
Dessa forma, sua capacidade superior remonta a posição ocupada pela mulher no passado.

Pode-se dizer que o mundo conheceu diferentes Sibilas. $\mathrm{Na}$ verdade, havia "muitas variantes do mito" ${ }^{2}$. Reza a lenda que a primeira delas era filha de Dárdano e de Neso, e, possuidora do dom de profetizar. Alguns estudiosos, porém, consideram como Sibila mais velha a filha de Zeus e de Lamia. Depois dessa surgiu Herófila, nascida em Tróade, fruto da união de uma ninfa e com um mortal.

Como ela viveu antes da guerra de Tróia, previu a ruína dessa mesma cidade por conta de uma representação feminina, - Helena-. Ela demonstrava ter uma relação bastante estreita com o deus Apolo: "Em Delos, havia um hino que ela compusera em honra de Apolo e no qual se dizia a 'mulher legitima' do deus e também a sua 'filha"” (Grimal, 2000: 416).

Essa Sibila viveu grande parte de sua vida em Samos, mas esteve, por períodos pequenos, em Claro, Delos e Delfos. Trazia sempre consigo uma pedra, na qual subia para exercer seu ofício e veio falecer em sua terra natal.

Todavia, a mais notável de todas elas é a Sibila de Éritras, da Líbia, filha também de ninfa e de mortal, - Teodoro -. Conta-se que, logo depois de ter nascido, ela começou a crescer, atingindo a altura de uma pessoa adulta; em seguida passou a vaticinar. Seus pais a consagraram ao templo de Apolo e viveu por muitos e muitos anos: "Diz-se que viveu nove vidas humanas, cada uma com cento e dez anos" (Grimal, 2000: 416).

Apolo concedera-lhe que vivesse tantos anos quantos os grãos de areia que sua mão pudesse conter, mas com a condição de que não mais voltasse a Éritras. Por esta razão, instalara-se em Cumas. Mas, tendo os Eritreus mandado, por descuido, uma carta cujo sela era em terra do seu país morreu.

Contava-se também que, tendo pedido uma longa vida a Apolo, que a amava e prometera satisfazer-lhe o primeiro desejo que formulasse, se esquecera de pedir também a juventude. $O$ deus ofereceu-lha em troca da sua virgindade, mas ela recusou. Assim, à medida que envelhecia, tornava-se cada vez mais pequena e ressequida, de tal modo que, por fim parecia uma

\footnotetext{
${ }^{2}$ BRANDÃO, Junito de Souza. Dicionário mítico-etimológico da mitologia grega. Rio de Janeiro: Vozes, 1991.
} 
cigarra e penduraram-na numa gaiola, como um pássaro, no templo de Apolo (Grimal, 2000: 416).

Sendo assim, da mesma maneira que Sibila ocupava uma posição de destaque em seu meio social, é possível verificar com base em estudos realizados por alguns antropólogos, que a figura feminina detinha um espaço privilegiado na sociedade celta, onde a era função masculina a caça de animais de pequeno porte e a procura de recursos naturais para sua alimentação e sobrevivência. Neste tipo de comunidade, a mulher era considerada um ser sagrado, por ser ela capaz de gerar vida. Por conseguinte, acreditava-se que ela poderia influenciar positivamente na qualidade do solo e na procriação de espécimes. Neste período não existia diferenças significativas entre sexos. A mulher ficava em casa cuidando dos filhos e tinha o poder de cura. Para Rose Marie Muraro, "nesses grupos, o princípio masculino e o feminino governam o mundo juntos. Havia divisão de trabalho entre os sexos, mas não havia desigualdade. A vida corria mansa e paradisíaca" (1997: 5).

Com o passar do tempo, surgiram grupos sociais que praticavam caçadas aos bichos maiores, nas quais era empregada a força física. Assim, principiava a superioridade do homem. A mulher, entretanto, ainda se mantinha um ser sagrado por conta de sua condição. Para a sociedade celta, a figura feminina tinha poderes, era representação da Soberania, a Grande Deusa. Logo, pode-se associar esta mulher a Sibila, pois de ambas emana uma energia, um poder sobre o homem. Era essa figura que absorvia paulatinamente a energia vital de Domingos Areal, conforme se observa na seguinte passagem do texto:

Porque o caso é que - fixádevos ben no párrafo a seguir - a partimos do intre en que Domingos Areal se apoderou da sortella coa a elipse, fronte á casa do triángulo dos Loureiros, cada noite revélaselle en soños unha fascinante persoa. Unha muller impar (Ferrín, 1980: 14).

Depois de certo período apareceram as fadas, representantes de um perfil moderno da Grande Deusa, mantendo, porém, as mesmas características da origem. Elas detinham o controle sobre o bem e o mal, portadoras de rara beleza, capaz de atrair os homens para as tramas amorosas. Dentre as principais personagens designadas por fada pode-se citar Morgana, proveniente do Círculo Arturiano. A ela cabe decidir sobre o futuro dos homens: 
A imagem maléfica de Morgana foi se acentuando. Ela passou de curadora e benéfica a destruidora e mortal. Ela assumiu verdadeiramente a função da mãe-amante, daquela que dá a vida e morte, da que destrói e regenera, transformando-se em figura perigosa, inquietante, mas sedutora.[...]

Morgana era aquela que amava, mas podia odiar a qualquer momento, com a mesma intensidade com que amava, e seu ódio se traduzia em vingança. A atitude de Morgana, que julgava e punia os cavaleiros que se desviavam de seu poder, não era muito diferente das damas que presidiam os Tribunais do Amor da ética cortês. Elas também absolviam ou condenavam aqueles que se desviavam do poder de sua dama (Barros, 2001: 281-2).

Por conta desse poder, conferido à mulher, de decisão sobre a vida e a morte dos homens com os quais ela se relacionava, surgiu o mito da feiticeira, pois:

os personagens dos mitos são os Entes Sobrenaturais. Eles são conhecidos, sobretudo pelo que fizeram no tempo prestigioso dos "primórdios". Os mitos revelam, portanto, sua atividade criadora e desvendam a sacralidade (ou simplesmente a "sobrenaturalidade") de suas obras. Em suma, os mitos descrevem as diversas, e algumas vezes dramáticas, irrupções do sagrado (ou do "sobrenatural") no Mundo (Eliade, 1972: 11).

Dessa forma, Sibila possui traços muito próximos de Morgana, personagem criada por Ferrín em seu conto, uma vez que é permitido a constatação de serem ambas as mulheres que transitam entre o alfa, - princípio - e o ômega, - fim -. Além disso, tal personagem ferriniana tem a função de atrair para o centro da narrativa, marcas de elementos fantásticos, sobrenaturais, maravilhosos, insólitos. Isso posto, faz-se oportuno tecer alguns comentários sobre o gênero Fantástico e suas variáveis.

Pode-se dizer que o Fantástico necessita da existência de situação angustiante, do assombro. Segundo Todorov, no citado gênero é estabelecida uma indecisão mediante o fato sobrenatural. Não é possível afirmar se este ocorreu realmente; pois existe uma hesitação, efeito que deixa o leitor sem saber qual a posição a ser tomada:

O fantástico ocorre nesta incerteza; ao escolher uma ou outra resposta, deixa-se o fantástico para se entrar num gênero vizinho, o estranho ou o maravilhoso. O fantástico é a hesitação experimentada por um ser que só conhece as leis naturais, em face de um acontecimento aparentemente sobrenatural (Todorov, 2007: 30-31).

Tal gênero, por conseguinte, se subdivide em Estranho e Maravilhoso. 
Entende-se por Fantástico Estranho quando há ocorrências extraordinárias, as quais são racionalmente explicadas. Acerca disso, Todorov afirma: "acontecimentos que parecem sobrenaturais ao longo de toda a história, no fim recebem uma explicação racional" (2007: 51). O Estranho Puro solicita por uma explicação racional. Corresponde a episódios impossíveis da narrativa, mas que podem ser esclarecidos pelas leis da razão: "Nas obras que pertencem a este gênero, relatam-se acontecimentos que podem perfeitamente ser explicados pelas leis da razão, mas que são de uma maneira ou de outra, incríveis, extraordinários, chocantes" (Todorov, 2007: 53).

Já no Fantástico Maravilhoso os fatos narrados permanecem como improváveis ou inexplicáveis até o final da narrativa, quando, então, são explicados por leis do sobrenatural. Sobre isso Todorov salienta:

Estamos no fantástico-maravilhoso, ou em outros termos, na classe das narrativas que se apresentam como fantásticas e que terminam por uma aceitação do sobrenatural. Estas são as narrativas mais próximas do fantástico puro, pois este, pelo próprio fato de permanecer sem explicação, não-racionalizado, sugere-nos realmente a existência do sobrenatural (2007: 58).

O Maravilhoso Puro acontece ao se constatar uma série de fatos na diegese que são considerados imprevisíveis e explicados desde o início do texto, por intermédio das leis do extraordinário, do mágico. Supõe-se a existência de outro mundo, conforme Todorov: "No caso do maravilhoso, os elementos sobrenaturais não provocam qualquer reação particular nem nas personagens, nem no leitor implícito.” (2007: 60).

Percebe-se, entretanto, com o passar dos tempos, o surgimento de mais outro gênero relativo a esta mesma estética, que recebeu a denominação de Realismo Maravilhoso. Tal viés literário apresenta nova forma de olhar a realidade, de por em prática recentes recursos narrativos que permitem a criação de imagem possuidora de vários sentidos acerca da realidade. Esse gênero possui como característica a ausência do medo, do horror, sendo manifestado no texto o encantamento, a magia. Despeito disso Irlemar Chiampi comenta:

O realismo maravilhoso desaloja qualquer efeito emotivo de calafrio, medo ou terror sobre o evento insólito. No seu lugar, coloca o encantamento como em efeito discursivo pertinente à interpretação não-antitética dos componentes diegéticos. $\mathrm{O}$ insólito, em óptica racional, deixa de ser o "outro lado", o 
desconhecido, para incorporar-se ao real: a maravilha é (está) (n) a realidade (1980: 59).

Em estudos recentes foi cunhada uma categoria acerca do Fantástico, que tem por incumbência abranger todas as demais classificações. Para o professor doutor Flávio Garcia $^{3}$, pautado em pesquisas realizadas em torno do Fantástico e suas vertentes, é oportuno o emprego da expressão "Insólito" com o objetivo de representar todos aqueles gêneros já mencionados, sem se vincular a nenhum. A propósito Garcia pondera:

Os eventos insólitos seriam aqueles que não são freqüentes de acontecer, são raros, pouco costumeiros, inabituais, inusuais, incomuns, anormais, contrariam o uso, os costumes, as regras e as tradições, enfim, surpreendem ou decepcionam o senso comum, às expectativas quotidianas correspondentes a dada cultura, a dado momento, a dada e específica experienciação da realidade.

É lícito opor o insólito ao natural e ao ordinário, termos comuns na teoria dos gêneros literários quando se quer falar de Maravilhoso, Fantástico, Estranho, Sobrenatural, Realismo Maravilhoso (2008: 19).

O pesquisador admite, ainda, a existência de ficções "que têm em comum a presença de eventos insólitos, e esses eventos sejam não ocasionais e funcionem como seu móvel, constitua um gênero" (2008: 18).

Por sua vez, as histórias julgadas fantásticas, sobrenaturais, enfim insólitas, permeiam um universo real, porém para se concretizarem é necessário a ocorrência do espanto, do extraordinário, da ansiedade, como se verifica na obra ficcional Sibila, já que "nem toda ficção, nem todo sentido literal está ligado ao fantástico; mas todo fantástico está ligado à ficção e ao sentido literal. Estas são pois condições necessárias para a existência do fantástico" (Todorov, 2007: 84).

Ferrín inicia o conto com o narrador relembrando episódios desagradáveis e estranhos vivenciados por ele e por seu amigo, de acordo com o seguinte fragmento do texto: "Rememoro a figura esguia daquel inesquecíbel Domingos Areal, avantando do

\footnotetext{
${ }^{3}$ Flávio Garcia é membro do corpo docente da Universidade do Estado do Rio de Janeiro, coordenador do SePEL - Seminário Permanente de Estudos Literários da UERJ e organizador dos Painéis "Reflexões sobre o Insólito na narrativa ficcional".
} 
esquenzo. E todo comenzara ao sairmos do cine (viramos Metrópolis) e reunírmono a cear na do Asesino, nunha fría, xeante noite do ano 1925" (Ferrín, 1980: 11). Logo, pode-se dizer que esta é uma narrativa em primeira pessoa, fato que colabora para a instauração de elementos desencadeadores de insegurança e característicos do fantástico, do insólito. A esse respeito Todorov assegura: "O narrador representado convém ao fantástico pois facilita a necessária identificação do leitor com as personagens. O discurso deste narrador possui um estatuto ambíguo" (2007: 94).

O personagem narrador, ao redigir suas reminiscências, intui que algo ruim irá acontecer novamente. Ele se encontra em um estado de grande atribulação ao lembrar que, estando junto de seu companheiro, caminhando pela Rua dos Loureiros, onde os dois acharam o anel. Cabe ressaltar o fato de esse objeto ser anunciador da aparição de Sibila, e, a partir desse momento Domingos Areal se tornou mais uma vítima de tal criatura, assim como no passado, outros homens sucumbiram ao poder de Morgana:

Estou - mentres escribo seguido sem cáseque erguer a pluma do papel - ateigado de anguria e de presaxio, dominado póla emoción dos tempos idos: altiva insurxencia que nos ollos levabamos. Todo podia ocorrer naquela noite [...]

Estabamos na Rua dos Loureiros, ollabamos unha fermosa casa (número 5) cuxa cima conformábase nun frontón triangular de pedra que reclamaba a miña atención cubista e a curiosidade teosófica de Domingos Areal. Un lóstrego - ou presencia inefábel - obrigounos, simultaneamente, a pór a vista no chan. $E$ estaba ali a sortella, brillando coma un luceiro. Precipitámonos os dous a apañala. Colleuna Domingos de primeiro e, nun xesto veloz, púxoa no dedo minguiño da man esquerda: lémbroo ben. Estendeu a man longa e dura e ollámo-la sortella á luz dun lampión. Ostentaba un signo semellante a unha elipse: ambos sentímonos na presencia do mistério (Ferrín, 1980: 12).

A posição de agonia assumida pelo narrador propicia a hesitação, pois não é possível determinar com clareza se a situação é real ou fruto de suas impressões, o tem como conseqüência um fenômeno fora do comum: "Há um fenômeno estranho que se pode explicar de duas maneiras, por meio de causas de tipo natural e sobrenatural. A possibilidade de se hesitar entre os dois criou o efeito fantástico" (Todorov, 2007: 31).

O espaço descrito na obra é bastante conhecido pela personagem que relata os acontecimentos. Ele descreve com riqueza de detalhes todo o percurso feito naquela noite: 
Camiñamos sen rumbo decidido, ambos embrulldos nos gabáns, os chapéus afundidos, as paipas fumegantes con orgullo: Rua do Medio, encastelada de podentes chaminés; Bonaval, coma un tránsito á cinsa e á miséria mesta que cada porta ou xanela bafexaban; os agros de Belvís recibindo xeada e silencio carregado de saudades, opaco; os Lagartos, canella tímida se as hai. Algún can latia nos confins da Compostela maldita mentres voltabamos de cara ao alivio da cidade con armas de pedra e chan lousado (Ferrín, 1980: 12).

Exatamente por isso, este ambiente pertence à rotina desse homem, cumprindo, uma das solicitações para a ocorrência do insólito, como Filipe Furtado assegura: “Assim, uma primeira característica do gênero vem à superfície: nele se encena o surgimento do sobrenatural, mas este é sempre delimitado, num ambiente quotidiano e familiar" (1980: 19).

Porém, no decorrer do mencionado conto, é possível admitir que o Fantástico propriamente não se sustenta. Tal condição permite que se investigue marcas do gênero Maravilhoso porque: "O fantástico leva pois uma vida cheia de perigos, e pode se desvanecer a qualquer instante. Ele antes parece se localizar no limite de dois gêneros, o maravilhoso e estranho, do que ser um gênero autônomo" (Todorov, 2007: 48).

Já foi dito que no Maravilhoso o incomum se mantém sem receber ou necessitar de uma explicação. Este gênero se manifesta na aparição de Sibila no decorrer dos sonhos de Domingos Areal:

Porque cada noite Sibila viña, viñalle. [...] viña carregada de roupaxes pesadas, inmóbil e dinâmica, e de cada retallo triangular da súa túnica surtia unha elipse musical e tenra que enchia todo o soño de Domingos cun arume estremecido de anduriña ou calquera cousa de fino e aletexante. (Ferrín, 1980: 16).

O mencionado gênero também se revela quando ela desaparece repentinamente, no momento que o rapaz desperta de seu sono: "Sentára-se Sibila e contemplara con ollos de aceiro e toda a maldade do mundo ao meu amigo, até que a albada e as campas viñeron rescatalo pra vixilia e pra luz, se é que ainda era rescatábel " (Ferrín, 1980: 16).

Sibila submetia Domingos Areal aos mais cruéis e humilhantes ritos, enquanto instrumentos musicais ecoavam no devaneio. Dos lábios da mulher jorravam uma substância purulenta e ela se mantinha despida e sentada no trono de bambu. Nos sofrimentos impostos ao jovem se registra, ainda, a presença do Maravilhoso: 
Cando a noite caía sóbor de Compostela, eu pensaba no meu amigo e compadecino de vez. Na soedade estricta da súa bufardia, tan pronto adormecia, entráballe Sibila pólo soño. E como eu coñecía a progresión das xeiras de tormento, sofria pelo meu camarata sofridor. Sibila impúñalle tratamentos nefandos: introducción de estiletes en partes inconfesábeis, masticación de cousas vermiculares, prácticas com escremento próprio e alleo: "Todo culmina sempre num êxtase perfecto" (Ferrín, 1980: 17).

A aflição vai se tornando cada vez mais intensa, tendo como conseqüência a morte daquele que era visitado pela estranha figura feminina.

Por ser sabedor de todos esses episódios, o narrador tem a certeza de que será o próximo a sofrer sob a tirania de Sibila, pois ele mesmo se depara com o enigmático anel:

E agora (reparade ben), dezaoito anos despois, neste 1943, que abriga no seu ventre todo o visgoso horror do mundo, escrebo esta memória, sen separar case a pluma do papel, pra deixa-la constancia conforme de que veño de atopar, fronte á casa número cinco da Rua dos Loureiros, fronte á casa do triángulo, a sortella coa elipse e que, a medida en que o meu escrito avanza na dirección do ponto final, vaise aproximando o intre decisivo en que entrarei no soño, serei ali visitado por Sibila, violência e fermosura iran dando conta deste narrador que olla con saudade as estrelas estáticas a través dun vidro embazado, a cidade máxica á que non culpo (Ferrín, 1980: 17 ).

Assim, consoante Flávio Garcia, a categoria Insólito está perfeitamente apropriada para abarcar o Fantástico, o Estranho e o Maravilhoso, já que evoca o sobrenatural sem estar enlaçado a nenhum dos gêneros em particular.

Pode-se concluir que a literatura permite o conhecimento das transformações ocorridas na história de uma sociedade. Verifica-se que a figura feminina, nos primórdios dos tempos, era respeitada e venerada por ser propagadora da vida. Com o passar dos tempos, nota-se Morgana como a grande representante desse poder. Na época atual, Ferrín apresenta Sibila como aquela que confirma e sustenta a soberania feminina.

Para realizar sua intenção o escritor galego emprega elementos sobrenaturais, extraordinários em sua narrativa, criando uma atmosfera de suspense e de intensa magia. 
Referências bibliográficas:

BARROS, Maria Nazareth Alvim de. As deusas, as bruxas e a Igreja: séculos de perseguição. Rio de Janeiro: Rosa dos Tempos, 2001.

BRANDÃO, Junito de Souza. Dicionário mítico-etimológico da mitologia grega. Rio de Janeiro: Vozes, 1991.

CHIAMPI, Irlemar. O realismo maravilhoso - forma e ideologia no romance hispano-americano. São Paulo: Perspectiva, 1980.

ELIADE, Mircea. Mito e realidade. São Paulo: Perspectiva, 1972.

FERRÍN, X. L. Méndez. Sibila. In: Crónica de nós. Santa Maria da Feira: Xerais de Galícia, 1980.

FURTADO, Filipe. A construção do fantástico na narrativa. Lisboa: Horizonte, 1980.

GARCIA, Flávio. O “insólito" na narrativa ficcional: a questão e os conceitos na teoria dos gêneros literários. In: GARCIA, Flávio (org). A banalização do insólito: questões de gênero literário: Mecanismos de construção narrativa - comunicações do I Painel Reflexões sobre o insólito na narrativa ficcional. Rio de Janeiro: Dialogarts, 2008.

LOPES, Ana Cristina M.; REIS, Carlos. Dicionário de narratologia. 7 ed. Lisboa: Almedina, 2007.

MURARO. Rose Marie. Introdução histórica. In: KRAMER, Heinrich; SPRENGER, James. O martelo das feiticeiras. 12 ed. Rio de Janeiro: Rosa dos Tempos, 1997.

PIERRE, Grimal. Dicionário da mitologia grega e romana. 4 ed. Rio de Janeiro: Bertrand, 2000.

PORTUGAL, Francisco Salinas. Ler Ferrín desde o Brasil. In: GARCIA, Flávio (org). Ler Ferrín; ler Galiza: estudos literários. Rio de Janeiro: Dialogarts, 2004.

REIS, Carlos. O conhecimento da literatura - introdução aos estudos literários. $2^{\text {a }}$ ed. Porto: Almedina, 2001.

TODOROV, Tzvetan. Introdução à literatura fantástica. 3 ed. São Paulo: Perspectiva, 2007. 